\title{
MUDANÇA SOCIAL E REAFIRMAÇÃO DA IDENTIDADE ENTRE OS TUKUNA DO BRASIL
}

Ari Pedro Oro*

O ano de 1972 é muito importante nả história dos índios Tukuna do Brasil. Com efeito, a partir dessa data a maioria deles se engajou na FRATERNIDADE DA SANTA CRUZ (FSC), ${ }^{1}$ um movimento de caráter messiânico, ${ }^{2}$ fundado por um "branco", brasileiro, vindo do Peru. Desde então esses índios conheceram uma mudança social tal que, em nossos dias, eles dividem a sua história em dois momentos distintos: em antes e em depois do aparecimento de José Francisco da Cruz. ${ }^{3}$

Pretendemos, nas páginas que seguem, analisar a situação dos Tukuna antes e como ela ficou após a sua adesão à FSC.

\section{I - OS TUKUNA ANTES DA FRATERNIDADE DA SANTA CRUZ}

Localizados na região do Alto Solimões, na fronteira do Brasil com o Peru e a Colômbia, distribuídos em vários povoados situados ao longo do rio Solimões e seus afluentes, sobretudo os da margem esquerda, os Tukuna formam a maior tribo indígena do Brasil com 19.000 índios, aproximadamente. Pelo que se sabe, eles sempre habitaram no interior da floresta, nas margens dos rios e igarapés da margem esquerda do rio Solimões, numa extensão de mais ou menos $250 \mathrm{~km}$, entre Tabatinga e São Paulo de Olivença. Os mesmos não foram contactados de maneira homogênea pelos brancos: os grupos mais próximos do Solimões receberam a visita dos missionários no princípio do século XVIII, enquanto que a maior parte deles ficou isolada e viveu longe do contato com os brancos até a metade do século XIX quando eles foram atingidos pelo "boom" da borracha que tomou conta do norte do Brasil no princípio do século XIX. Um número importante desses índios foi então engajado nessa empresa econômica, marcando profundamente seu futuro destino. 


\section{A dependência aos "barracões"}

A utilização industrial da borracha no mercado internacional atraiu um certo número de empreendedores, denominados patrões ou barões da borracha, ou simplesmente "seringalistas", os quais se instalaram ao longo dos rios da Amazônia para explorar aquele produto. Eles erigiram suas habitações, os "barracões", nas margens dos rios. Os barracões eram também casas comerciais. Os patrões utilizavam como mão-de-obra tanto os índios que habitavam na região quan to os brancos, vindos, como eles, em sua maioria, de outras regiões do norte e do nordeste brasileiro na esperança de fazer fortuna.

Quanto aos Tukuna, seu território foi invadido primeiramente pelos "caucheros" peruanos e depois pelos "seringueiros" brasileiros. Esses pioneiros eram violentos, não hesitando em bater nos índios, ou em aprisionálos, caso eles se recusassem a colaborar. Mais tarde, os castigos foram substituídos por meios indiretos de persuasão, apoiados principalmente numa tradição de violência. "Assim criou-se o mito do poder do seringalista". ${ }^{4}$ Ao mesmo tempo, para forçar os índios a participar dessa atividade econômica, os patrões adotaram a estratégia de introduzir junto a eles bens ocidentais como açúcar, sal, fósforos, armas, anzóis, cachaça, instrumentos de ferro e de aço, e outros mais, em troca dos trabalhos realizados. No fundo, o objetivo dos patrões era criar novas necessidades nos índios; era a manipulação pelas mercadorias. E os proprietários conseguiram seu objetivo, pois no fim de um certo tempo os elementos de origem ocidental estavam de tal maneira integrados na vida quotidiana dos índios que eles se tornaram indispensáveis. É nesse momento que os patrões colocaram em prática um rigoroso regime de exploração da mão-de-obra Tukuna: o "regime do barracão". 5

Segundo o regime estabelecido, os trabalhadores do "seringal" eram obrigados se munir de tudo o que necessitavam para a produção do látex, bem como para a sua subsistência, unicamente no barracão do seringal. Cada trabalhador possuía ali uma conta aberta na qual eram marcadas a sua produção e as suas retiradas. Em tais transações os índios analfabetos eram duramente explorados. É fácil compreender que no citado processo os patrões ganhavam duas vezes; a saber: no alto preço fixado pelos bens adiantados aos trabalhadores, e no baixo preço estabelecido pela sua produção. Diante dessa realidade, os trabalhadores não tinham como evitar o constante endividamento, o que os obrigava a continuar a trabalhar para tentar saldar o seu débito. Isto significa que, de alguma forma, os trabalhadores dos seringais eram prisioneiros do seu próprio trabalho. 
Em certos lugares e em certos momentos, os Tukuna foram submetidos a uma série de proibições tais como: "manter suas plantações de subsistência...", 6 pescar, comerciar com os "regatões", isto é, com os comerciantes ambulantes. $\mathrm{O}$ objetivo de tais medidas era fazer com que os índios ocupassem todo o seu tempo nos trabalhos relacionados ao barracão, e não produzissem sua própria alimentação, impedindo assim que abandonassem as atividades nos seringais.

$\mathrm{Na}$ realidade, os Tukuna nunca seguiram a risca tais normas. Como diz Oliveira Filho, enquanto os homens trabalhavam na extração da borracha, acompanhados dos seus filhos maiores, suas mulheres, filhas e filhos menores, trabalhavam nas suas plantações. ${ }^{7}$ Assim, os índios puderam conjugar a extração da borracha com a pesca, a agricultura e outras atividades, apesar das ordens contrárias ditadas pelos patrões.

Para reproduzir o mencionado sistemá de dominação, os patrões se aproveitavam dos chefes Tukuna. Caso eles se recusassem a colaborar, os patrões chegavam ao ponto de destituí-los dos seus cargos. Diante disso, os chefes Tukuna se encontravam numa situação ambígua visto que eles eram condenados a mentir a seus compatriotas para agradar aos patrões, e a mentir a estes últimos para não serem desprezados pelos seus. ${ }^{8}$ Nimuendaju assinala que, em 1929, conhecera vários desses chefes, os quais acabaram sendo mortos pelos seus em razão do estranho comportamento posto em prática. ${ }^{9}$

Para manter a dependência dos trabalhadores aos barracões, os patrões do Alto Solimões fizeram também, largamente, uso da cachaça. Construiu-se mesmo uma destilaria naquela região, na década de trinta, funcionando até 1964.

É necessário observar que a crise da borracha brasileira, iniciada em 1912, não liberou os índios dos barracões, embora, em certos lugares, sua situação melhorasse ligeiramente. Os índios foram então ocupados em outros setores econômicos como a extração da madeira, a agricultura, a produção da farinha de mandioca, a caça de animais com peles comercializáveis e a pesca.

É somente na década de 1940 que o sistema servil ao qual os Tukuna estavam presos começa a se desfazer. A mudança é devida primeiramente à instalação, no ano de 1942, de um posto do Serviço de Proteção dos Indios (SPI) em Tabatinga, transferido, porém, para Umariuaçu, em 1945. Esse organismo governamental desempenhou, durante anos, o papel de uma espécie de "Comissariado de Indios", investigando as denúncias feitas contra os proprietários locais. $\mathrm{O}$ posto servia igualmente de refúgio aos índios em conflito com os patrões. Em tais ações o SPI era às vezes ajudado pelo exército. Esses dois organismos federais estabeleceram uma nova relação de for- 
ças na região impedindo, ao menos parcialmente, a liberdade de açã̃o dos patrões em relação aos índios. ${ }^{10}$ A partir da década de 1960, esses organismos se impuseram ainda mais sobre as elites econômicas locais, que tiveram dificuldade para manter o monopólio comercial e a dominação política e econômica imposta aos índios.

$\mathrm{O}$ desenvolvimento de Letícia, cidade colombiana situada na margem esquerda do rio Solimões, na fronteira com o Peru e o Brasil, e de Benjamin Constant, vila brasileira situada na margem direita do rio Javari, teve também grande importância para quebrar a estrutura tra dicional de exploração da mão-de-obra indígena, na medida em que esses núcleos urbanos ofereceram uma alternativa para aqueles que não queriam comercializar com os regatões e os barracões. ${ }^{11}$

Enfim, é necessário assinalar que a presença entre os indígenas de membros da Prelazia do Alto Solimões e de pastores batistas também contribuiu para a modificação das relações de trabalho e de trocas de mercadorias entre os índios e os patrões, bem como com os comerciantes ambulantes.

\section{Os Tukuna após a descaracterização do regime do barracão}

Acabamos de ver como os índios foram submetidos aos patrões e como a situação histórica regional mudou, limitando o uso dos mecanismos de punição e de opressão das elites locais. Mas, paradoxalmente, a situação global dos Tukuna não melhorou. Saindo de uma estrutura opressiva, eles se sentiram, de uma certa maneira, numa situação paradoxal: de um lado o retorno ao sistema tradicional de vida não era mais possível de ser realizado, e, de outro lado, a falta de meios os impedia de obter uma melhor integração no mundo dos brancos.

Com efeito, o contato interétnico secular acarretou um tal número de modificações na cultura tradicional que a ruptura total com a sociedade envolvente era irrealizável. Vejamos alguns exemplos das modificações em questão: certos instrumentos de madeira e de osso utilizados tradicionalmente na caça e na agricultura foram substituídos pelos de metal; a cultura do algodão e do fumo foram abandonadas na medida em que nas suas trocas os Tukuna recebiam as vestimentas prontas e os pacotes de cigarros ou o próprio fumo; o sistema de trabalho coletivo, denominado "ajuri", ${ }^{12}$ perdeu o seu valor, sobretudo simbólico, e se tornou cada vez mais raro; o individualismo foi acentuado visto que durante o período da borracha cada índio recebia um tratamento individual: cada um possuía suas árvores para extração do látex e tinha sua conta no barracão; os produtos que tradicionalmente possuíam um valor de uso tornaram-se mercadorias tendo um valor de 
troca; a moeda, identificada pelos índios como manifestação do poder dos brancos, foi vivamente desejada para participarem desse poder.

As modificações ocorreram também em outros setores: os chefes locais não foram mais escolhidos segundo as regras da tradição, sobretudo em razão da influência sempre mais crescente dos patrões e dos membros dos organismos governamentais e das igrejas; o xamã perdeu gradativamente seu poder em razão do uso corrente dos medicamentos ocidentais e das intervenções praticadas pelos médicos e pelos missionários; os índios procuraram se alfabetizar afim de diminuir a distância que os separa dos brancos; os rituais tradicionais, mormente o de nominação das crianças, tornaram-se raros; o batismo ocupou, de certo modo, o seu lugar: o universo mítico e religioso Tukuna tornou-se sincrético diante da ação de evangelização realizada pelos missionários ao longo das décadas.

Os poucos exemplos citados mostram tanto as transformações pelas quais os Tukuna passaram ao longo do contato com o mundo ocidental quanto o nível de desagregação social no qual esses índios se encontravam ultimamente. Isto quer dizer que, se de um lado, as agências governamentais e confessionais de fato contribuíram para a desarticulação do "regime do barracão", de outro lado, elas não foram capazes de proporcionar aos indios a reorganização social e a retomada do sentimento de segurança e de dignidade perdidas. Isto significa que as mudanças ocorridas na região, a partir de 1940, não contribuíram para a melhoria das condições de vida dos índios. Conseqüentemente, eles continuaram a fazer parte da camada social mais desfavorecida, encontrando-se, como dissemos acima, numa situação de "dupla marginalidade". Esse impasse começará a se dissolver, para um número expressivo deles, no início de 1972.

\section{II - OS TUKUNA APÓS A FRATERNIDADE DA SANTA CRUZ}

José Francisco da Cruz se considerava portador de uma importante missão recebida em visão: a de reformar a religião cristã e de preparar a humanidade para o fim dos tempos que se aproxima. Com tal objetivo, ele abandonou sua esposa e seus filhos e, durante dez anos, peregrinou por todos os estados do centro e do sul do Brasil, bem como por todos os países do Prata. Ele não permaneceu por longo tempo em nenhum lugar, salvo no Peru, na região da selva, onde pregou durante três anos. Depois daquela estada ele entrou no Brasil seguindo o curso do rio Solimões. Após um ano de vida pública, nessa região brasileira, ele se retirou para o meio da floresta, onde residiu durante oito anos, até a sua morte, ocorrida em junho de 1982. 
J.F. da Cruz chegou à região brasileira precedido de uma grande reputação de ser portador de urn poder extraordinário, capaz de atos fora do comum como o de curar os doentes e de ser onipresente. Em razão de tal reputação um número importante de Tukuna, que vivia até então no interior da mata, se dirigiu em direção das vilas Tukuna, situadas nas margens do Solimões, para assistir a passagem desse personagem. Em seguida, outros povoados formaram-se nas margens do grande rio, ou de seus afluentes, em razão das migrações Tukuna. Nos dias atuais, os quase 13.000 Tukuna que se converteram a $\mathrm{FSC}^{13}$ se reúnem em cerca de 30 povoados.

\section{A organização dos povoados}

J.F. da Cruz deixou constituído um Diretório, composto de nove membros, em cada povoado que passou. Cada membro tem uma missão a cumprir no seu seio. O Diretor se ocupa das atividades religiosas: ele preside os cultos diários $;^{14}$ o Presidente e o Capitão são os responsáveis pela organização do trabalho no interior dos povoados; o Inspetor e o Procura-dor zelam pelo bom comportamento das pessoas segundo as normas propostas pelo fundador da FSC; as tarefas do Secretário, do Tesoureiro, do VicePresidente e do Vice-Secretário, são definidas de maneira imprecisa.

A existência dos Diretórios não significa que haja uma estrutura oligárquica de poder nos povoados da FSC. Se, de fato, as decisões referentes a certas atividades quotidianas são tomadas preferencialmente no âmbito dos Diretórios, os quais em geral as tomam em conselho, outras são tomadas com a participação de toda a comunidade.

Os membros dos Diretórios se ocupam de todos os setores da vida das comunidades. Tudo o que diz respeito à religião "stricto sensu", bem como à organização da produção e da comercialização, às relações sociais no interior dos povoados e destes com a sociedade envolvente, tudo isso é levado em consideração. Conseqüentemente, os Diretórios preenchem uma tarefa importante: eles contribuem para a existência de uma ordem no interior das comunidades, eles estão atentos às necessidades dos "irmãos", eles as discutem e propõem soluções.

\section{0 trabalho e a cooperação}

Existem dois pontos em que J.F. da Cruz chamou especial atenção dos seus seguidores para os mesmos obterem a "salvação nesta terra", isto é, melhorarem as condições terrenas de vida; são eles: a cooperação mútua e a dedicação ao trabalho agrícola. 
J.F. da Cruz sabia que a agricultura, a pesca e a caça, constituíam as atividades econômicas mais importantes dos Tukuna. No entanto, ele observou que a partir das últimas décadas as dificuldades para a obtenção de peixes e de caça aumentaram na região. Daí, ele insistiu, junto aos seus fiéis, para se dedicarem à agricultura afim de melhor garantirem a própria subsistência e aumentarem o seu poder econômico.

Tradicionalmente os Tukuna faziam plantações individuais e/ou familiares e todos os membros da família se beneficiavam da produção. De tempos em tempos eles faziam também os "ajuris", isto é, trabalhos coletivos para a preparação da terra nas plantações individuais. J.F. da Cruz reforçou a necessidade de continuar a trabalharem nas plantações individuais, mas, ao mesmo tempo, ele solicitou aos seus fiéis para que trabalhassem em plantações comunitárias. $\mathrm{O}$ mesmo acreditava estar assim melhor organizando a produção agrícola nas comunidades da sua religião.

Em nossos dias, existem povoados on de não há plantações comunitárias e outras onde há uma, duas ou até mais. A coordenação de tais trabalhos é do encargo dos Diretórios locais. A dimensão das roças varia entre um e oito hectares, aproximadamente. Não se trabalha ali durante todo o ano, mas somente em certos períodos, seja para preparar a terra seja para efetuar a colheita que diversifica, segundo o produto. Em tais trabalhos participam os homens, as mulheres e as crianças.

Nas plantações comunitárias cultivam-se de preferência os produtos destinados ao mercado como o milho, o arroz, a banana, o ananás, a mandioca, com a qual se faz a farinha. A comercialização é feita nos centros regionais brasileiros (Benjamin Constant e Tabatinga), ou colombianos (Leticia), ou peruanos (Ramon Castillo), seja em dinheiro seja em troca de bens de uitilização comum como o café, o açúcar e o sal, (que são consumidos nos trabalhos coletivos ou em outros encontros como as procissões mensais que têm lugar em cada povoado), o querosene, as velas (utilizadas nas igrejas); a madeira e o zinco (necessários para construir ou reparar a igreja ou uma casa destinada ao uso coletivo); a tinta, para pintá-los; o tecido para fazer as bandeiras, etc. A venda dos produtos em dinheiro é normalmente feita quando a comunidade possui o projeto de adquirir certos bens mais onerosos e que exigem uma certa poupança como motores para as canoas, ou mesmo barco a motor. Até o momento, ao menos três povoados Tukuna adquiriram um barco a motor cada um. Tais barcos estão, em princípio, à disposição de todos os componentes de cada comunidade.

Mais do que as plantações comunitárias, as plantações individuais são postas no primeiro plano pelos Tukuna. É, com efeito, nesse trabalho que as farnilias se consagram quotidianamente e donde elas tiram a subsistência ou os produ tos destinados ao mercado. $\mathrm{O}$ "ajuri" continua a ser posto em práti- 
ca. O rendimento das plantações individuais é mais elevado do que aquele das plantações comunitárias em razão da utilização mais intensa e mais coordenada da mão-de-obra familiar e individual.

As informações referentes ao preço dos produtos, a equivalência das diferentes moedas, circulam normalmente entre os "irmãos da Santa Cruz", (como se auto-denominam os adeptos da FSC), o que lhes permite limitar as perdas por ocasião das transações comerciais.

Essas breves considerações permitem concluir que em nossos dias os Tukuna possuem um certo poder de controle sobre sua produção e sobre sua comercialização, contrariamente ao período anterior à sua adesão à FSC e sobretudo àquele onde eles estavam sob o poder dos patrões.

\section{Nova atitude em relação ao dinheiro}

Um outro ponto importante para obter a "salvação", no sentido que lhe dá J.F. da Cruz, é a poupança do dinheiro e a estocagem de certos produtos. Com efeito, o fundador da FSC aconselhava os seus fiéis a estocarem sal, açúcar e querosene, especialmente. A reserva será, conforme ele, necessária para enfrentar os tempos difíceis que se aproximam. ${ }^{15}$ J.F. da Cruz aconselhava também a negociarem somente após terem refletido bem, a colocarem de lado qualquer centavo e todo dinheiro possível para comprar mais tarde uma casa, um terreno, ou simplesmente para poderem melhor alimentar seus familiares. Quanto ao dinheiro comunitário, fruto das plantações coletivas ou das coletas dos cultos dos domingos, ele deve ser guardado para construírem mais tarde uma igreja, ou uma escola, e, se possível, um orfanato e um abrigo para os pobres.

$\mathrm{O}$ fundador da FSC aconselhava ainda os seus fiéis a depositarem seu dinheiro num banco. Até o momento, porém, os Tukuna preferiram guardar o fundo comunitário, quando eles o possuem, em suas comunidades. Quanto ao dinheiro individual, ou ele é utilizado para adquirir os bens manufaturados, necessários no seu dia a dia, ou ele é guardado em vista de aquisições ulteriores mais importantes como folhas de zinco para cobrir suas moradias, roupas, e, eventualmente, motores para suas canoas.

Os raros índios que utilizam os serviços dos bancos existentes nas cidades da região fazem-no com certa dificuldade, visto que, segundo a lei, ${ }^{16}$ estes atos devem ser realizados por intermédio do organismo tutelar, a Fundação Nacional do Índio - FUNAI. 


\section{O puritanismo de conduta:}

Falando de si mesmos, os Tukuna da Santa Cruz dizem que antes da chegada de J.F. da Cruz eles estavam constantemente bêbados e que isto acarretava brigas e mortes. Os dados etnográficos confirmam tais testemunhos. Os "ajuris" e os rituais acabavam, muitas vezes, em bebedeira dos participantes, e mesmo em assassinatos. ${ }^{17}$ J.F. da Cruz, por sua vez, proibiu terminantemente as bebidas alcoólicas, o fumo, as festas, e mesmo os rituais tradicionais em que ocorria a ingestão de bebidas fermentadas.

Os "irmãos" valorizam de tal maneira a abstinência da bebida alcoólica que eles se distinguem por este traço do resto da população, especialmente da católica que qualificam de "o povo do copo".

O controle social e a vigilância mútua sobre esses pontos é grande nos povoados da Santa Cruz, isto porque, em nossos dias, eles revelam ter consciência dos efeitos nefastos que a bebida alcoólica produzia outrora na estrutura familiar e social. Por ocasião de nossas enquetes, eles manifestaram igualmente ter consciência de que o abandono do cigarro e da aguardente permite-lhes poupar dinheiro e assim adquirir aqueles bens e produtos úteis na vida quotidiana, mas que antes eles não podiam conseguir por falta de recursos.

$\mathrm{O}$ que precede permite observar que após a adesão à $\mathrm{FSC}$ o individualismo e o comunitarismo caminham juntos entre os Tukuna; a promoção do indivíduo é acompanhada da promoção de todos os membros da comunidade; há uma valorização da economia mas também de outros setores da vida social; enfim, há uma tendência em diminuir as desigualdades sociais e não em acentuá-las.

\section{A reafirmação da identidade}

Na atualidade, os Tukuna da Santa Cruz se mobilizam não para retornar a um suposto "passado tribal", concebido como uma "idade de ouro", mas para melhor participar dos bens, do conforto e do conhecimento do mundo dos brancos. Essa dinâmica social revela o desejo desses índios de alcançar "melhores condições de integração social", segundo a expressão de Oliveira Filho. ${ }^{18}$ De fato, por intermédio da FSC os Tukuna querem superar a condição de "objetos" de integração, fazendo parte da camada social mais desfavorecida, para se tornar "sujeitos" da sua integração, mestres do seu destino, fixando eles mesmos os limites dessa integração.

Tal integração é acompanhada do desejo Tukuna de salvaguardar a identidade própria, isto é, de pertencer a um grupo social que possui suas 
particularidades e que se distingue dos demais grupos sociais. Isto se manifesta pela manutenção da língua Tukuna e de sua utilização nos cultos, pela concentração em "novas" comunidades, pela maneira singular de ser e de se portar. Eles manifestam ainda sua especificidade pelo porte de um uniforme e pelo uso extensivo da cruz.

"O uso do uniforme, diz um Diretor Tukuna, serve para distinguir o povo da Santa Cruz dos outros". ${ }^{19}$ Quanto à cruz, ela é o símbolo maior dos "irmãos da Santa Cruz". Visto sua importância, ela é trazida em torno ao pescoço, pintada ao lado das portas de entrada das habitações, nos instrumentos musicais, nas costas das camisas dos homens e dos vestidos das mulheres. Uma cruz, de cerca de trinta centímetros, é também posta em evidência no interior das moradias dos "irmãos" e dos seus barcos. A cruz torna-se assim um meio importante pelo qual os Tukuna se reencontram e se identificam como grupo. A função desse simbolismo é de caracterizar o grupo, de afirmar o "nós" diante dos "outros". A identidade se afirma assim como o resultado das relaçōes entre os grupos sociais, ${ }^{20}$ ou mesmo como sua oposição. Em todo o caso a identidade não se afirma isoladamente. ${ }^{21}$

A identificação dos Tukuna em torno da FSC não implica porém numa renúncia de seus sinais tradicionais de pertença étnica. Esta se apóia sobre a ocupação de um território dado, sob a forma de lugar mítico e de lugar de produção, sobre um idioma particular, sobre a relação com um passado histórico e mítico, e principalmente sobre a estrutura de parentesco, de tipo dual - as metades sendo "árvores" e "aves" - formando um sistema que Levi-Strauss denominou de "hiper-totêmico". ${ }^{22}$ Em cada metade há um certo número de clans patrilineares. O que tradicionalmente define a identidade Tukuna é o vínculo das crianças ao clan paterno.

A esses critérios tradicionais vem se acrescentar, em nossos dias, para um número significativo de Tukuna, mais um importante elemento de identificação. ${ }^{23}$ Isto significa que a FSC permitiu, a uma parte importante desses índios, não somente reafirmar a sua identidade mas, até certo ponto, reconstruí-la, ${ }^{24}$ para continuar a se manter como grupo diferenciado no seio da sociedade global.

Percebe-se, pelos fatos aludidos, a reivindicação de um grupo indígena que quer continuar a ser indígena, ou melhor, Tukuna, (e para tanto faz uso dos referenciais que julga oportuno), e ao mesmo tempo quer conquistar o seu espaço no seio mesmo da sociedade global. Em outras palavras, os Tukuna da Santa Cruz reivindicam uma integração mais digna no mundo dos brancos sem serem por ele assimilados. 


\section{CONCLUSÃO}

Antes da sua adesão à Fraternidade da Santa Cruz os Tukuna se encontravam numa situação de desorganização tribal fruto do tipo de contato imposto ao longo das décadas mormente por uma certa categoria de nãoíndios. Esses índios se encontravam também num impasse visto que o retorno ao passado tribal era praticamente impossível de ser realizado e a participação mais intensa ao mundo ocidental que eles desejavam era-lhes barrado. Era, segundo os próprios índios, uma época de "obscurantismo", de "vícios", de "bebedeiras".

$\mathrm{O}$ período posterior à adesão à FSC é, ao contrário, caracterizado pelos Tukuna como o da "verdade", da "ordem", da "luz", do "progresso", da "vida". Com efeito, a mensagem globalizante e modernizadora de J.F. da Cruz veio ao encontro das aspirações dos índios. Além do mais, o fundador forneceu os meios para entrarem no espaço novo ao qual desejavam aceder mas que não encontravam na ajuda fornecida pelas igrejas e os organismos de Estado que atuavam até então junto a eles. J.F. da Cruz, por seu turno, tinha consciência do que fazia; ele se propôs, com efeito, "civilizar os pobrezinhos", segundo as suaș próprias palavras.

Para concluir podemos dizer que por intermédio da FSC os Tukuna conhecem uma mudança social favorável, a qual atinge todos os domínios da existência, e se reencontram enquanto grupo, nas novas comunidades, onde a vida volta a ter um sentido porque eles agem em vista de um novo presente e de um novo futuro. Resta saber se tais tendências, que predominaram nesses treze anos de existência da FSC, se confirmarão, uma vez que este movimento está ainda se constituindo e se estruturando. Além do mais, seus membros, que manifestam o interesse de manter estreitas relações com a sociedade envolvente, só poderão continuar a ser eles mesmos e a concretizar as próprias aspirações se gozarem da tolerância e da proteção das autoridades e dos membros desta última. Como afirmou B. Wilson, sem tolerância e relativa proteção de parte da sociedade maior nenhum grupo religioso consegue se desenvolver e se manter. ${ }^{25}$ 


\section{NOTAS}

${ }^{1}$ Cerca de 12.000 entre 19.000 Tukuna aderiram à FSC. Mas há outro tanto de nãoíndios, ribeirinhos da região, que também se consideram membros da FSC.

Neste artigo nossa análise se restringirá unicamente às implicações relativas ao engajamento dos indígenas à FSC.

2 Denomina-se "movimento messiânico" o movimento cujo líder repousa a sua autoridade numa revelação divina e reúne em torno de și um certo número de pessoas, formando uma "comunidade emocional", onde todos agem em vista da realização do "paraíso" aqui nesta terra. (Sobre a definição de movimento messiânico, ver sobretudo COHN, Norman. Les fanatiques de l'Apocalypse. 2.ed. Paris, Payot, 1983, pp.9-10; e PEREIRA DE QUEIROZ, Maria Isaura. Réforme et Révolution dans les sociétés primitives. Histoire et Ethnologie des mouvements messianiques. Paris, Ed. Anthropos, 1968; também, da mesma autora, Images messianiques du Bresil. Cuernavaca (México), Sondeos, n.87, 1972).

${ }^{3} \mathrm{~F}$. Isambert, entre outros, enfatizou o relevante significado histórico que representa para um grupo determinado o aparecimento de um messias.

"O messias, escreve este autor, absorve em si mesmo a história que se encontra dividida num antes e num depois radicalmente descontínuos. $\mathrm{O}$ aparecimento do Messias é o evento histórico por excelência, aquele que dá à história toda a sua significação, aquele em quem toda a história se resume" (ISAMBERT, François. "Fondateurs, Papes et Messies" in: Archives de Sociologie des Religions. Paris, n.5, janeiro-junho 1958, p.98).

${ }^{4}$ CARDOSO DE OLIVEIRA, Roberto. O Indio e o Mundo dos Brancos. 2.ed. São Paulo, Livraria Pioneira Ed. 1972, p.57.

${ }^{5}$ Note-se que esse regime afetou tanto os índios quanto os não-índios.

${ }^{6}$ CARDOSO DE OLIVEIRA, Roberto. A Sociologia do Brasil Indigena. Rio de Janeiro, Ed. Tempo Brasileiro, 1978, p.181.

${ }^{7}$ OLIVEIRA FILHO, João Pacheco de. As facções $e$ a ordem politica em uma reserva Tukuna. Brasilia, Universidade de Brasília, 1975, p.45.

${ }^{8}$ NIMUNDAJU, Kurt. The Tukuna. Berkeley and Los Angeles, University of California Press, 1952, p.65.

$9_{\text {Ibid. }}$

10 OLIVEIRA FILHO, J.P. de. As facções e a ordem politica em uma reserva Tukuna. op. cit., pp.63-64.

${ }^{11}$ CARDOSO DE OLIVEIRA, R.C. de. A sociologia do Brasil indigena. op.cit., p.55. 12 "Ajuri" é uma palavra do idioma Tupi e significa reunião, encontro, sobretudo por motivos econômicos. Entre os Tukuna outrora sobressaía o aspecto cerimonial do "ajuri" pelos cantos e danças que eram realizados em tais circunstâncias.

Visto que a palavra "ajuri" é provavelmente a deturpação da palavra "ajuda", Nimuendaju levantou a possibilidade dos Tukuna não conhecerem essa instituição antes do contato com os brancos. No entanto, o mesmo autor observa também "que é necessário levar em consideração a possibilidade dos Tukuna conhecerem o "ajuri", os quais somente adotaram a forma atual e a terminologia portuguesa" (NIMUENDAJU, C. The Tukuna, op. cit., p.54). 
${ }^{13}$ Os demais Tukuna se consideram ou católicos ou protestantes batistas.

${ }^{14}$ As condições de acesso ao posto de Diretor são três: ser casado, ter sido batizado no "batismo das águas", e, sobretudo, ser alfabetizado, isto é, capaz de ler a bíblia. Ê por causa dessa última exigência que J.F. da Cruz afirmava ter escolhido um número importante de não-índios para ocupar o cargo de Diretor, mesmo em certos povoados indígenas.

Em regra geral, o fundador designava os titulares dos postos mais importantes dos Diretórios, a saber: o Diretor, o Capitão e o Presidente, ratificando nos outros postos os nomes sugeridos pelos seus "discípulos"' mais imediatos. Esse fato deixava uma certa margem a colocação em prática de um certo número de interesses pessoais.

${ }^{15}$ Tal procedimento não é porém ainda posto em prática a não ser de maneira bem tímida.

${ }^{16}$ Trata-se dos artigos 7 a 11 da Lei Federal n. 6.001 de 11 de dezembro de 1973 que regulamenta o estatuto do índio.

${ }^{17} \mathrm{Cf}$. Frei Fidelis de ALVIANO. "Notas etnográficas sobre os Indios Tucunas do Alto Solimões". In: Revista do Instituto Histórico e Geográfico Brasileiro. Rio de Janeiro, Imprensa Nacional, V.180, pp.19-20; R.C. de OLIVEIRA. $O$ Indio e o mundo dos Brancos. op.cit., p.53; et C. NIMUENDAJU. The Tukuna. op.cit., pp.52 e ss.

18 OLIVEIRA FILHO, J.P. de. "A difícil etnografia de uma tribo em mudança". In: Anuário Antropológico. 1979, Rio de Janeiro, Ed. Tempo Brasileiro.

Os conceitos de integração e de assimilação não são sinônimos. No primeiro caso a participação econômica e social do grupo tribal na sociedade ocidental não the faz perder a sua identidade. No segundo caso, há a incorporação quase total da sociedade indígena, mesmo das suas particularidades culturais e da sua identidade étnica, no seio da sociedade ocidental envolvente (Cf. sobre esse tema: Roque de BARROS LARAIA. "Integração e Utopia". In: Revista de Cultura Vozes. Petrópolis, Ano 70, n.3, 1976, p.13; e Darcy RIBEIRO e outros: "Un concepto sobre integracion social". In: America Indigena. Mexico, n.1, V.XX, 1960,p.9.

A política indigenista de "integração", preconizada pela FUNAI, corresponde a uma vontade de assimilação dos índios na sociedade nacional, isto é, de fazê-los abandonar a sua "indianidade" para tornarem-se "verdadeiros brasileiros". Pelo que sabemos, até o mom ento nenhum grupo indígena foi assimilado à sociedade nacional; eles foram ou integrados, em graus diversos, segundo os grupos (o que demonstra a vontade dos índios de continuarem a ser eles mesmos), ou eliminados pelas epidemias, doenças e violências perpetradas contra eles.

${ }^{19}$ O uniforme é o mesmo desde o início do movimento: as mulheres usam um longo vestido branco, com mangas longas, e os homens usam uma calça e uma camisa, também brancas. Normalmente eles vestem o uniforme nos domingos e nos dias feriados, quando participam dos cultos e quando se deslocam nas cidades.

${ }^{20}$ Segundo M.A. Hily, “...o que funda a identidade de um povo é a sua relação ao "outro" (...). Pode-se adiantar que o conceito de identidade deve ser considerado como - resultado de variáveis produzidas no campo das relações entre os grupos sociais" (HILY, Marie-Antoinette. "La résistance a l'assimilation". In: Autrement. Paris, n.11, novembro 1977 , pp.87 e 90).

${ }^{21}$ CARDOSO DE OLIVEIRA, Roberto. Identidade, etnia e estrutura social. São Paulo, Livraria Pioneira Ed. 1976, p.5. 
${ }^{22}$ LEVI-STRAUSS, Claude. La pensée sauvage. Paris, Plon, 1962, p.147.

${ }^{23}$ Ser Tukuna e ser membro da FSC são pois em nossos dias duas modalidades pelas quais um certo número desses índios põe em evidência a sua singularidade étnica e social. Mas não pertencer a FSC não significa nẩo ser mais Tukuna. Dessa forma, os Tukuna católicos e os batistas se consideram Tukuna tanto quanto os Tukuna da FSC. Estes, por sua vez, não recusam aos demais a identidade Tukuna, apesar de alguns indícios contrários constatados no início do movimento.

${ }^{24} \mathrm{C}$. Levi-Strauss chamou a atenção para o fato de que a problemática comum das sociedades exóticas e da nossa "é que a identidade se reduz menos a postulá-la ou a afirmá-la do que a refazê-la, reconstruí-la" (LEVI-STRAUSS, Claude. L'identité. Paris, PUF, 1983, p.331).

${ }^{25}$ WILSON, Bryan. "Apparition et persistance des sectes dans un milieu social en évolution". In: Archives de Sociologie des Religions. Paris, n.5, janeiro-junho 1958, p.142.

*Departamento de Ciências Sociais

Pontifícia Universidade Católica do RS

90620 Porto Alegre - RS 